\title{
Didactique des Sciences Physiques
}

Jean-Michel Dusseau

\section{(2) OpenEdition}

Journals

Édition électronique

URL : http://journals.openedition.org/trema/2303

DOI : $10.4000 /$ trema.2303

ISSN : 2107-0997

\section{Éditeur}

Faculté d'Éducation de l'université de Montpellier

\section{Édition imprimée}

Date de publication : 1 mai 1993

Pagination : 1-1

ISSN : 1167-315X

\section{Référence électronique}

Jean-Michel Dusseau, « Didactique des Sciences Physiques », Tréma [En ligne], 3-4 | 1993, mis en ligne le 21 décembre 2010, consulté le 22 septembre 2020. URL : http://journals.openedition.org/trema/ 2303 ; DOI : https://doi.org/10.4000/trema.2303

Ce document a été généré automatiquement le 22 septembre 2020.

Trema 


\section{Didactique des Sciences Physiques}

Jean-Michel Dusseau 
Ce numéro double de la revue de l'IUFM de Montpellier est consacré aux Actes du "Deuxième Séminaire National de Recherche en Didactique des Sciences Physiques"; qui s'est déroulé à Sète les 18-19 et 20 octobre 1992. Le choix de TRF.MA, facilité par des raisons géographiques évidentes, s'est imposé naturellement. En effet, la structuration par le comité scientifique de ces journées en trois parties (communication de travaux de recherche contenant des expérimentations proprement didactiques, présentation d'innovations pédagogiques, ateliers sur le thème: "Quels types de connaissance apportent les recherches didactiques mettant en jeu des séquences d'enseignement ?»), permet une approche à plusieurs niveaux des problèmes liés à l'enseignement des Sciences Physiques. Et en cela nous sommes au coeur de la raison d'être des IUFM.

Est-il raisonnable, même si les Sciences Physiques sont plurielles de consacrer un numéro double à une seule discipline? Au travers de ces Actes, les questions posées, les méthodologies employées, les éléments de réponses obtenus ne peuvent qu'enrichir les réflexions menées sur l'enseignement d'autres disciplines.

Enfin pour les vocations de recherche que la lecture de ce numéro de TREMA ne manquera pas de susciter, quelques attentes relatives aux thèses de Didactique des Sciences Physiques y sont mentionnées.

Il m'est agréable de remercier l'Université MONTPELLIER Il, l'Union des Physiciens, le CNRS (Groupement de recherche $n^{\circ}$ 07) et l'IUFM de Montpellier pour leur soutien financier.

\section{RÉSUMÉS}

Non disponible

Not available 
AUTEUR

JEAN-MICHEL DUSSEAU

IUFM de Montpellier 